\title{
Cancer mortality among workers in the Tuscan tanning industry
}

\author{
ADELE SENIORI COSTANTINI, E PACI, LUCIA MILIGI, EVA BUIATTI, \\ CRISTINA MARTELLI, S LENZI
}

From the Centro per lo Studio e la Prevenzione Oncologica, 50132 Florence, Italy

\begin{abstract}
The mortality of 2926 male workers at the tanneries in the "leather area" of Tuscany was examined from 1950 to 1983 comparing it with the national mortality. Cancer mortality was of particular concern because of the many chemicals known to be definite or suspected carcinogens used in the tanning cycle, in particular chromate pigments, benzidine based dyes, formaldehyde, and organic solvents. There was no excess of deaths for cancers of all sites but slight increases in deaths from cancer of the lung $(S M R=131$, CI 95\% $=88-182)$, bladder (SMR $=150$, CI 95\% $=48-$ 349), kidney (SMR = 323, CI 95\% = 86-827), pancreas (SMR = 146, CI 95\%=39-373), and leukaemias $(\mathrm{SMR}=164, \mathrm{CI} 95 \%=53-382)$ occurred. Two cases of soft tissue sarcomas were observed versus 0.09 expected (SMR $=2178, \mathrm{CI} 95 \%=250-8023)$.
\end{abstract}

Chemical substances known to be carcinogenic for man and animals have been used in the tanning industry for many years. ${ }^{1-3}$ It has not been clearly established if workers handling these materials are at an increased risk of developing cancer. Several studies have shown an increased risk of tumours of nasal cavity sinuses, ${ }^{4-6}$ bladder, ${ }^{7-11}$ pharynx, lung, ${ }^{1213}$ and of the haemopoietic and lymphopoietic systems ${ }^{8}$ among leather workers but few studies have dealt specifically with tannery workers.

In a large case-control study on cancer of the bladder conducted in Boston, showing an increased risk for leather workers in general, an increased risk associated with tanning operations was not significant. ${ }^{7}$ No evidence of an increased risk of developing cancer was suggested by a cohort mortality study conducted in England. ${ }^{14}$ Similar negative results were reported by Stern in a large cohort mortality study concerning people engaged in two chrome tanneries in the United States. ${ }^{15}$ Others have reported an excess of malignant tumours of the intestine ${ }^{16}$ and of cancer of the stomach and pancreas ${ }^{17}$; in addition, an excess risk of cancer of the lung ${ }^{13}$ and of the kidney ${ }^{18}$ has been suggested.

In Tuscany (Italy) leather production is a major industry and tanneries are concentrated in an area named the "leather area" in the provinces of Florence and Pisa.

Accepted 9 January 1989
We have conducted a cohort mortality study in this area; of particular concern were cancers of the lung and urinary tract because chromates known to be carcinogenic for the lung and benzidine based dyes for the bladder were used.

\section{Materials and methods}

The leather area covers six municipalities in Florence and Pisa. There were 90152 inhabitants in 1981. The tanning industry developed in the 1950 s and is now the main industry in the area. In 1980 there were about 850 firms with about 7300 employees according to a local census. Most of the tanneries are small, often installed in old, unsuitable buildings, with no means of environmental control and little automation. In recent years there has been some improvement of existing premises and the construction of new factories.

Tanning is carried out in this area with natural or synthetic tannins or chrome salts; some factories combine the two methods. There is a much greater use of dyes, pigments, and solvents in the factories using the chrome process; in the traditional tanning of leather dyes are seldom used. In 1981-2 an environmental survey was conducted in a sample of $83 \mathrm{firms} .{ }^{19}$ More than 2900 different products were listed, of which about 1000 were dyes. The use of some known or suspected carcinogens was noted, including benzidine based dyes, orthodianisidine based dyes, orthotolidine based dyes used for colouring in drums, hexavalent chrome salts used as pigment in finishing 
operations, formaldehyde used in various phases of the tanning process, and chlorophenols including pentachlorophenol used as preservatives. The presence of $\mathrm{N}$-nitrosodimethylamine derived from dimethylaminosulphate and used as an accelerator in the dehairing stage has been reported in the work environment of some tanneries. ${ }^{1}$ There is no such evidence in the Tuscan tanneries examined in 1981-2.

The cohort was selected from the records kept by the employment office of one municipality, Santacroce sull' Arno, in which most of the chrome tanneries are located. The decision to use this source was determined by the absence of complete company records and the rapid turnover of the firms themselves, with frequent changes of trade names. The employment office began its activity in May 1950 and since then has kept information on nearly all residents either employed or looking for work. Industries are required by law to hire employees through the employment office and, in the rare cases in which the office is not directly concerned, it must nevertheless be informed of the hiring and this information is recorded on the worker's employment record. For all citizens who have ever sought employment or changed employment since 1950 an individual employment record exists at the office. This card records the first employment in the industry (date, employer) and the subsequent changes to other firms. When a worker was first employed before 1950 but came to the office when subsequently changing employer, the record was completed; employment before 1950 was also registered. Therefore the only group of workers who would systematically be excluded from these records are those first employed before 1950 and who did not change employer after 1950. In the tanning industry there would be few of these, because before 1950 production was small.

The following information is available for each worker: date and place of work, residence while looking for work, date of starting work, date of finishing work, type of industry, and name of employer. The specific job is also recorded but most workers have the simple title operaio (worker) because the small size of most firms and the skilled operations used generally means that each worker is regularly engaged in most or all the steps in the tanning process.

The reliability of the employment office as a source of data for epidemiological studies was examined by Merler $e t$ al in Arzignano in the province of Vicenza (N Italy) where there is another important tanning complex. ${ }^{20}$ The authors, who used this source to enumerate a cohort of workers engaged in the local tanneries, compared information on the working history from the employment office with information collected by telephone. The results indicated a high level of agreement between the two sources of data.
Of the 7955 individuals listed in the Santacroce sull'Arno Employment Office file from May 1950 to 31 December 1981, 4196 were recorded as tanners. The present analysis refers to 2926 male workers who have worked in the tanneries of the area for at least one continuous period of six months or more (table 1). Workers were included even when the date of first employment in the tanning industry occurred before 1950. Follow up and accumulation of person-years at risk began in 1950 or the year of first employment in the tannery industry as registered at the Santacroce sull'Arno Employment Office if this was later and continued until 30 June 1983. Information on vital status was obtained from the official records of the municipalities (both of residence where they were first registered and in those to which they may have subsequently moved). Causes of death were classified according the the ICD (8th rev).

The analysis used the computer program designed for cohort studies by Monson in which observed deaths, expected deaths, and SMRs are calculated for five year calendar periods and five year age groups. ${ }^{21}$ Standard death rates were the Italian cause specific death rates for $1961,1966,1971$, and 1976 . Two sided confidence intervals $(95 \%)$ for SMRs were calculated according to Byer's formula and Mantel and Haenszel chi-squared tests were performed where appropriate. ${ }^{21}$ An analysis of duration between first exposure and death was also carried out and the chi-squared test for trend was calculated with a Poisson trend statistic. ${ }^{22}$

\section{Results}

Only four workers of the 2926 were lost to follow up and not included in the analysis. The cohort was young with an average age of 45 and an average period of 15 years follow up. About $75 \%$ of the subjects entered the cohort when they were under 39 . The average duration of employment was about seven years.

Table 2 shows observed deaths, expected deaths, and SMRs for major causes of death. Mortality for all causes was significantly less than expected $($ SMR $=69)$, the mortality deficit being mostly in circulatory diseases $(S M R=47)$; there was no evidence of a deficit for tumours (SMR $=97$ ).

Table 1 Male tannnery workers cohort identified through the Santacroce sull'Arno Employment Office records (195081)

\begin{tabular}{lrr}
\hline & No & $\%$ \\
\hline Workers registered as tanners & 2926 & 100 \\
Alive at the end of follow up & 2669 & $91 \cdot 21$ \\
Dead & 253 & $8 \cdot 65$ \\
Lost to follow up & 4 & $0 \cdot 14$ \\
Person-years of follow up & 44033 & \\
\hline
\end{tabular}


Table 2 Mortality of 2922 male tanners from 1950 to 1983: observed deaths, expected deaths, SMRs, and CI 95\% for major causes of death

\begin{tabular}{|c|c|c|c|c|}
\hline Cause of death (ICD 8th rev) & Obs & $\operatorname{Exp}$ & $S M R$ & CI95\% \\
\hline Overall mortality (001-998) & 253 & $365 \cdot 26$ & $69^{*}$ & $61-78$ \\
\hline Infective diseases $(001-138)$ & 3 & 8.03 & 37 & $7-109$ \\
\hline All neoplasms $(140-239)$ & 85 & $87 \cdot 87$ & 97 & $77-119$ \\
\hline $\begin{array}{l}\text { Circulatory diseases (390- } \\
458 \text { ) }\end{array}$ & 67 & $142 \cdot 31$ & $47^{*}$ & $36-60$ \\
\hline $\begin{array}{l}\text { Respiratory diseases (460- } \\
519)\end{array}$ & 18 & $25 \cdot 88$ & 70 & $41-109$ \\
\hline $\begin{array}{l}\text { Digestive tract diseases } \\
\quad(520-577)\end{array}$ & 25 & $31 \cdot 94$ & 78 & $51-115$ \\
\hline Violent deaths (800-998) & 31 & $34 \cdot 91$ & 89 & $60-126$ \\
\hline
\end{tabular}

Table 3 shows observed deaths for specific cancer sites and table 4 observed, expected deaths, and SMRs for cancer sites with four or more observed cases.

Table 4 shows that SMRs were increased, but not significantly, for cancers of the kidney, pancreas, bladder, and lung, and leukaemias. Cancer of digestive organs were, by contrast, significantly lower, with a SMR of 68; this deficit was mostly accounted for by the SMR for stomach cancer which was 43.

Because many tanners (around $25 \%$ ) were born in southern Italy, where the mortality for cancers of digestive tract are much lower than in central or northern Italy, a further analysis was carried out for the subcohort of 2074 subjects born in Tuscany. The results did not differ significantly from the previous analysis, with SMR of 41 (CI 95\% = 14-97) for stomach cancer. No differences were noted for other causes of death. Analyses by duration of employment and of follow up showed no trends except for bladder

Table 3 Mortality of 2922 male tanners from 1950 to 1983: number of observed deaths for specific cancer sites ( 84 malignant neoplasms*)

\begin{tabular}{lr}
\hline Cause of death (ICD 8th rev) & No \\
\hline Pharynx (140) & 1 \\
Oesophagus (150) & 3 \\
Stomach (151) & 6 \\
Large intestine (153) & 3 \\
Rectum (154) & 2 \\
Liver and gall bladder (155-156) & 2 \\
Pancreas (157) & 4 \\
Other digestive cancers (159) & 1 \\
Lung (162) & 29 \\
Soft tissue sarcomas (171) & 2 \\
Malignant melanoma (172) & 2 \\
Prostate (185) & 2 \\
Bladder (188) & 5 \\
Kidney (189) & 4 \\
Cancers not better specified (195-199) & 8 \\
Hodgkin's disease (201) & 2 \\
Leukaemias (204-207) & 5 \\
Other haematopoietic malignancies (200, 209) & 3 \\
Total & 84 \\
\hline
\end{tabular}

*The number of all neoplasms was 85 including a benign tumour (ICD 210).
Table 4 Mortality of 2922 male tanners from 1950 to 1983: observed deaths, expected deaths, SMRs, and CI 95\% for cancers with four or more observed deaths

\begin{tabular}{|c|c|c|c|c|}
\hline Cause of death (ICD 8th rev) & $O b s$ & $\operatorname{Exp}$ & $S M R$ & CI $95 \%$ \\
\hline $\begin{array}{l}\text { Digestive tract }(150-159) \text { : } \\
\text { Stomach }(151) \\
\text { Pancreas (157) } \\
\text { Lung (162) } \\
\text { Bladder (188) } \\
\text { Kidney (189) } \\
\text { Haemolymphopoietic system } \\
\text { (200-209): } \\
\text { Leukaemias (204-207) }\end{array}$ & $\begin{array}{r}21 \\
6 \\
4 \\
29 \\
5 \\
4 \\
10\end{array}$ & $\begin{array}{r}30 \cdot 76 \\
13 \cdot 88 \\
2 \cdot 74 \\
22 \cdot 04 \\
3 \cdot 34 \\
1 \cdot 24 \\
6 \cdot 54 \\
\\
3 \cdot 05\end{array}$ & $\begin{array}{c}68 \\
43^{*} \\
146 \\
131 \\
150 \\
323 \\
153\end{array}$ & $\begin{array}{l}42-104 \\
16-94 \\
39-373 \\
88-182 \\
48-349 \\
86-827 \\
73-288 \\
53-382\end{array}$ \\
\hline
\end{tabular}

cancer where the SMR increased with latency: $\mathrm{SMR}=0$ for $<15$ years, 155 for $15-19$ years, 277 for 20-24 years, and 390 for 25-29 years; this trend was not statistically significant. All bladder cancers occurred in workers who entered the cohort between 1950 and 1964.

Among the more rare tumours of suspected occupational origin there were two cases of soft tissue sarcomas versus 0.09 expected $(\mathrm{SMR}=2178, \mathrm{CI}$ $95 \%=250-8023)$. No case of sinonasal cancer occurred in the cohort.

\section{Discussion}

The results of this study suggest that there is no overall increased risk of tannery workers developing cancer. This conclusion, however, must be tempered by the fact that the period of follow up is rather short to allow for the appearance of solid tumours. The fact that mortality for all causes was significantly less than expected is consistent with the "healthy worker effect."

The low SMR for cancer of the stomach is difficult to explain. These data conflict with the results of a Swedish study ${ }^{17}$ which showed an excess risk of stomach cancer among tannery workers and with an Italian study in which an excess risk of digestive cancer was observed. ${ }^{16}$ Tuscan death rates are available only for 1970-9 but in that period the rates for all cancer sites do not notably differ from national rates except for stomach cancer which is always higher in Tuscany ${ }^{23}$ (while nevertheless following the same decreasing trend over time as in the rest of Italy). In particular, a mortality study of residents in Santacroce sull' Arno, in the period 1969-79 found the rates for digestive tract cancers to be significantly raised compared with the national rates in the period 1960-9 but then slightly lower than national rates in the period 1970-9. In this study SMRs for stomach cancer among the tannery population were, however, lower in both periods examined. Thus whereas Tuscany is generally 
known as a region of high stomach cancer, this pattern appears to be modified by socioeconomic and nutritional factors. ${ }^{24}$ Possibly, therefore, the low risk among tannery workers may be explained by their socioeconomic status (in Tuscany tannery workers are well paid artisans with stable employment) and also by the absence of strong occupational risk factors for stomach cancer. This hypothesis is being investigated as part of a large case-control study on diet and stomach cancer now under way. ${ }^{25}$

The slight increase in cancer of the pancreas is consistent with the findings of Edling et al. ${ }^{17}$ Evidence of an association between pancreatic cancer and smoking, alcohol, coffee consumption, and some occupational carcinogens is suggested in several studies, but there has been no evidence of an association with any specific chemical used in tanning. It would be interesting to examine this further.

A slight, but non-significant, excess of lung cancer was shown in the cohort. In a cohort study conducted in the United States a significant increase of lung cancer was found, ${ }^{13}$ whereas this has not been confirmed by most other studies in this sector. ${ }^{141517} \mathrm{~A}$ risk factor for lung cancer may be the use of trivalent chrome salts which can contain hexavalent salts as impurities. The two bath tanning method in which hides are saturated with hexavalent chrome salts and then placed in a bath that reduces the dichromate to trivalent chrome sulphate has not been generally used since the second world war. Hexavalent salts are used as pigments in finishing operations but in small amounts. A study conducted on $\mathbf{3 0 0}$ male workers in the tanneries of the area showed a greater frequency of metaplasia and moderate dysplasia in sputum cells by comparison with a sample of the population resident in the same area and working as clerks in public administration, controlling for age and smoking habits. ${ }^{26}$ Tannery workers did not smoke with greater frequency than clerks $(0.57 v 0.63)$. No information was available on past smoking habits, but it is unlikely that tannery workers smoked more than the general population. Indeed, Stern has suggested that the nature of tannery work may actually decrease the amount that these workers smoke. ${ }^{15}$ Altogether these findings suggest that additional research is justified to evaluate further the hypothesis that there is a raised risk of lung cancer in this occupation.

Leukaemias showed a slight excess in the cohort (5 observed $v 3$ expected). An association between leukaemias and employment in the leather industry occurs in several studies but there is no specific mention of tanning operations.

The excess of kidney and bladder cancers are of particular concern because of the use in the tanning cycle of dyes and pigments derived from aromatic amines. An increased risk of kidney cancer for tannery workers was suggested by Malker et al, ${ }^{18}$ whereas many studies have indicated an association between bladder cancer and working in the leather trade ${ }^{79-11}$; the excess risk has not been related to tanning operations, however. It was not possible to verify whether deaths from renal cancer were due to renal parenchyma or excretory tract cell cancers. In the tanning process and mainly in the finishing department of chrome tanneries in the leather area an extremely large amount of dyes and pigments is used, among which are some bladder carcinogens (benzidine based dyes, orthotolidine based dyes, orthodianisidine based dyes). ${ }^{19}$

Possibly in the past two or three decades there has been considerable exposure to the chemicals used, owing to a lack of protective measures. Probably also benzidine based dyes were in greater use in the past and subsequently they have been partially replaced by others with less carcinogenic potency. The slight increase in this study of bladder cancer in the tannery workers of this area may be explained by the use of these products.

Two cases of soft tissue sarcomas occurred versus 0.09 expected. There is no mention in published reports of an excess of soft tissue sarcomas in tannery workers, except in one study in which one sarcoma was observed versus 0.07 expected. ${ }^{14}$ Although the small numbers make it difficult to interpret these data, it should be mentioned that in the beam house (the pretanning operations) and in the tanning operations chlorophenols, which have been associated with these malignancies, are used.

Finally, it will be important to continue to follow up this cohort for some years as the numbers of observed deaths are still small and the period of exposure rather short.

The study was possible thanks to the cooperation of the nursing personnel of the epidemiology section of the CSPO, in particular of Mascia Bongini, Lea Nastasi, and Gabriella Perotti who collected the information from the Santacroce sull'Arno Employment Office and from the registry offices of the municipalities of the leather area. We also thank the local tanning associations and the municipal administration offices who kindly cooperated with the nursing staff.

We thank Professor $\mathbf{R}$ Saracci, International Agency of Research for Cancer, Lyon, for his helpful suggestions and Dr D Kriebel, Harvard University, Boston, for his help with the English text.

The search was partially supported by the Regional Government of Tuscany. 


\section{References}

1 International Agency for Research on Cancer. Monographs on the evaluation of the carcinogenic risk of chemicals to humans. Vol 25. Wood, leather and some associated industries. Lyon: IARC, 1981.

2 International Agency for Research on Cancer. Monographs on the evaluation of the carcinogenic risk of chemicals to humans. Vol 23. Some metals and metallic compounds. Lyon: IARC, 1980.

3 National Institute for Occupational Safety and Health. Health hazard alert benzidine, o-tolidine and o-dianisidine based dyes. Washington: NIOSH-OSHA, 1980.

4 Acheson ED, Cawdell RH, Jolles B. Nasal cancer in the Northamptonshire boot and shoe industry. Br Med J 1970; i:385-93.

5 Cecchi F, Buiatti E, Kriebel D, et al. Adenocarcinoma of the nose and paranasal sinuses in shoe makers in the province of Florence-Italy (1963-77). Br J Ind Med 1980;37:222-5.

6 Merler E, Baldasseroni A, Laria R, et al. On the causal association between exposure to leather dust and nasal cancer: further evidence from a case control study. $\mathrm{Br}$ J Ind Med 1986;43:91-5.

7 Cole P, Hoover R, Friedel GH. Occupation and cancer of lower urinary tract. Cancer 1972;29:1250-60.

8 Decoufle P. Cancer risk associated with employment in the leather and leather production industry. Arch Environ Health 1979; 34:33-7.

9 Marret LT, Hartge P, Meigs JW. Bladder cancer and occupational exposure to leather. $\mathrm{Br} J$ Ind $\mathrm{Med}$ 1986;43:96-100.

10 Vineis P, Magnani C. Occupation and bladder cancer in males: a case control study. Int J Cancer 1985;35:599-606.

11 Wynder EL, Onderdonk J, Mantel N. An epidemiologic investigation of cancer of the bladder. Cancer 1963;16:1308-1407.

12 Coggon D, Pannet B, Osmond C, Acheson ED. A survey of cancer and occupation in young and middle aged men. I Cancers of the respiratory tract. Br J Ind Med 1986;43:332-8.
13 Garabrant DH, Wegman DH. Cancer mortality among shoe and 3 leather workers in Massachusetts. Am J Ind Med 1984;5:303-14.

14 Pippard EC, Acheson ED, Winter PD. Mortality of tanners. Br J Ind Med 1985;42:285-7.

15 Stern FB, Beaumont JJ, Halperin WE, et al. Mortality of chrome $\stackrel{\vec{S}}{\vec{S}}$ leather tannery workers and chemical exposure in tanneries. Scand J Work Environ Health 1987;13:108-17.

16 Puntoni R, Valerio A, Cresta E, et al. Studio di mortalità tra i lavoratori di una conceria. Med Lav 1984;75:471-6.

17 Edling C, Kling H, Flodin U, Axelson O. Cancer mortality among leather tanners. Br J Ind Med 1986;43:494-6.

18 Malker HR, Malker BK, McLanghein JK, Blot WJ. Kidney cancer among leather workers. Lancet 1984;i:56.

19 Regione Toscana-Giunta Regionale. Mappe di Rischio Oncologico in Ambiente di Lavoro. Il Settore Conciario. Firenze: Regione Toscana, 1986.

20 Merler E, Schierano S, Ricci P, et al. Verifica della storia lavorativa in uno studio di coorte: concordanze fra fonti diverse. Med Lav 1988;78:487-95.

21 Monson RR. Analysis of relative survival and proportional of mortality. Comput Biomedical Research 1974;7:325-32.

22 Breslow NE, Day NE. Statistical methods in cancer research. Vol 2. The design and analysis of cohort studies. Lyon: International Agency for Research on Cancer, 1987. (IARC sci publ 82.)

23 Rapporti ISTISAN. La mortalità in Italia nel periodo 1970-79. S Rome: Istituto Superiore di Sanita', 1984.

24 Palli D, Buiatti E, Cipriani F, Trallori G. Aspetti epidemiologici del carcinoma gastrico, in epidemiologia dei tumori in Italia. Stato dell'arte. Trento: Temi Editrice, 1987.

25 Buiatti E, Amadori D, Avellini C, et al. Multicentric case-control $\vec{\theta}$ study on diet and gastric cancer in Italy. Cancer Lett 1988; 39:543.

26 Seniori Costantini A, Buti R, Dolara P, et al. Monitoring carcinogenic risks in tannery workers by means of desquamative lung and bladder cytology and urinary mutagenicity. Ann Occup Hyg 1987;31:21-30. 